\title{
Análise de crescimento de duas cultivares de cevada após tratamentos com elicitores e fungicidas
}

\author{
Growth analysis of two barley cultivars after elicitors and fungicides treatment
}

\author{
Noemir Antoniazzi ${ }^{1}$ Cícero Deschamps ${ }^{2}$
}

\section{RESUMO}

Para o controle da mancha marrom da cevada, causada pelo fungo Bipolaris sorokiniana, têm sido utilizados fungicidas e mais recentemente foi proposto o uso de elicitores. O objetivo deste trabalho foi avaliar o desenvolvimento de duas cultivares de cevada cervejeira, "BRS 195” e "BRS 225”, em resposta à aplicação de elicitores goma xantana e alicina e do fungicida epoxiconazole + pyraclostrobin, comparativamente a plantas não tratadas. O experimento foi conduzido na Fundação Agrária de Pesquisa Agropecuária (FAPA), Guarapuava - PR, no delineamento de blocos completos casualizados. Na análise de crescimento, foram determinados o índice de área foliar (IAF), a taxa de crescimento relativo (TCR) e a taxa assimilatória líquida (TAL). Observou-se desenvolvimento semelhante das cultivares em todos os tratamentos. A cultivar "BRS 225” registrou maior acúmulo de matéria seca no período de avaliação por apresentar um ciclo vegetativo mais curto. O IAF aumentou até a fase de emborrachamento das plantas, com posterior decréscimo. A TCR diminuiu da primeira para a última coleta. A TAL diminuiu até 57 dias após a emergência, seguindo aumento no decorrer das avaliações.

Palavras-chave: goma xantana, alicina, desenvolvimento vegetal.

\section{ABSTRACT}

In order to control barley boun spot, caused by Bipolaris sorokiniana, fungicides and more recently elicitors have been used. The objective of this work was to evaluate the development of two barley cultivars (BRS 195 and 225) in response to treatment with two elicitors xanthan gum and alicin and the fungicide epoxiconazole + pyraclostrobin compared with non treated control plants. The experiment was carried out at Fundação Agrária de Pesquisa Agropecuária (FAPA), Guarapuava - PR, in a randomized complete block design. In the growth analysis, they were performed calculating the leaf area index (LAI), relative growth rate (RGR) and net assimilation rate (NAR). A similar development was observed for both cultivars in all treatments. The cultivar BRS 225 showed higher dry weight accumulation during the evaluation period than cultivar BRS 195 because of its shorter vegetative growth phase. The LAI increased until the boot stage following decrease. The $R G R$ decreased from the first to the last evaluation. The NAR decreased until 57 days after emergency and then increased during all remaining evaluations.

Key words: xanthan gum, alicin, plant development.

\section{INTRODUÇÃO}

A cevada no Brasil é cultivada quase que exclusivamente para fins cervejeiros, sendo seu cultivo concentrado nos estados do Paraná, Rio Grande do Sul e Santa Catarina (TONON, 1992). Nesta região, vários fungos atacam a cultura, sendo Bipolaris sorokiniana o causador de uma das mais sérias doenças (TURQUETI et al., 2001), pois ataca as espigas, causando descoloração e escurecimento na ponta dos grãos e conseqüente diminuição da qualidade do malte e da cerveja (ARIAS, 1995). Como agravante, as cultivares de cevada cervejeira atualmente recomendadas são suscetíveis ao Bipolaris sorokiniana, sendo necessária a adoção de medidas de controle eficientes para evitar prejuízos no rendimento e na qualidade cervejeira (EMBRAPA, 2003).

Para o controle dessa doença em cevada, o uso de fungicidas tem sido uma medida bastante

${ }^{I}$ Curso de Pós-graduação em Agronomia, área de concentração Produção Vegetal, Universidade Federal do Paraná (UFPR), Curitiba, PR, Brasil. E-mail: noemir@agraria.com.br.

${ }^{2}$ Curso de Pós-graduação em Agronomia, área de concentração Produção Vegetal (UFPR), Rua dos Funcionários, 1540, CP 19061, 88035-050, Curitiba, PR, Brasil. E-mail: cicero@ufpr.br. Autor para correspondência. 
utilizada pelos agricultores. Contudo, o elevado custo e os riscos de contaminação ambiental e de intoxicação durante a aplicação são bastante conhecidos. Uma das alternativas no combate das doenças é a indução de resistência através do uso de elicitores. Estes compostos têm sido extensivamente avaliados no controle de doenças de espécies vegetais (GUZZO et al., 1993; BENHAMOU, 1996; GATZ, 1997). Em plantas de trigo, foi observado controle de Bipolaris bicolor, Bipolaris sorokiniana, e Drechslera tritici-repentis após tratamento com goma xantana (BACH, 1997; BACH et al., 2003). O elicitor alicina foi recentemente avaliado, em condições de casa de vegetação, na indução de resistência contra Bipolaris sorokiniana nas cultivares de cevada "Embrapa 128” (RODRIGUES et al., 2002) e “AF 94135” (RODRIGUES et al., 2003). Em ambos os casos, os autores constataram uma proteção de 100\% no intervalo de 72 horas após a aplicação, atribuindo sua eficácia a alterações bioquímicas tais como o aumento da concentração de proteínas e da atividade da enzima beta 1,3 glucanase e a diminuição da concentração de fenóis. CASTRO et al. (2001 e 2002) observaram resultados semelhantes na indução de resistência em nível local e sistêmico utilizando goma xantana como elicitor, proporcionando uma proteção superior a 90\%, atribuindo também esta indução a síntese e ao acúmulo maiores da enzima beta 1,3 glucanase.

Apesar dos resultados promissores do ponto de vista de controle deste patógeno, há de se avaliar ainda se a aplicação desses produtos interfere no desenvolvimento vegetativo e, consequentemente, no rendimento da cultura em condições de campo. Estudos têm demonstrado que a resposta aos elicitores envolve, na maioria das vezes, a síntese de compostos secundários e, portanto, a indução da resistência pode alterar o particionamento de carbono e consequentemente o desenvolvimento vegetal. Segundo HERRMMANN \& WEAVER (1999), a rota do chiquimato, responsável pela formação de grande parte destes compostos, é considerada uma das vias principais de fluxo de carbono nas plantas. Para avaliar o desenvolvimento vegetal e inferir sobre a contribuição de diferentes processos fisiológicos no desenvolvimento vegetal, a análise de crescimento é levada em consideração (BENINCASA, 1988).

O objetivo deste trabalho foi investigar a resposta no desenvolvimento das plantas de cevada cultivares “BRS 195” e “BRS 225”, após a aplicação dos elicitores goma xantana e alicina e do fungicida epoxiconazole + pyraclostrobin, em comparação com plantas não tratadas.

\section{MATERIAL E MÉTODOS}

O experimento foi instalado na área experimental da Fundação Agrária de Pesquisa Agropecuária (FAPA), distrito de Entre Rios, Guarapuava - PR, sobre um solo classificado como Latossolo Bruno Alumínico típico, textura argilosa, fase campo subtropical (EMBRAPA, 1999), a 25 $33^{\prime} \mathrm{S} ; 51^{\circ}$ 29' W, com 1105 metros de altitude, com as seguintes características químicas na profundidade de 0 a $10 \mathrm{~cm}$ :

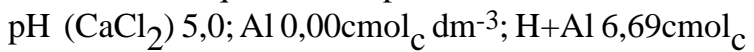

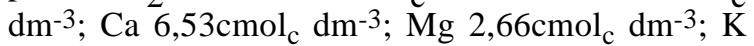
0,54 $\mathrm{cmol}_{\mathrm{C}} \mathrm{dm}^{-3}$; P 31,2mg dm-3; MO 55,62 $\mathrm{g} \mathrm{dm}^{-3}$; V 59,3. O clima, segundo Köppen, é classificado como temperado do tipo $\mathrm{Cfb}$, sendo a temperatura média no mês mais frio inferior a $18^{\circ} \mathrm{C}$ (mesotérmico) e no mês mais quente abaixo de $22^{\circ} \mathrm{C}$.

$\mathrm{O}$ experimento foi conduzido seguindo as "Indicações Técnicas para Produção de Cevada Cervejeira: Safras 2003 e 2004” (EMBRAPA, 2003). A semeadura foi realizada no sistema plantio direto na palha, em área cultivada anteriormente com soja. As parcelas foram compostas por 12 linhas de $5 \mathrm{~m}$ de comprimento, com entrelinhas de $0,17 \mathrm{~m}$, a uma densidade de 250 e 280 sementes viáveis $\mathrm{m}^{-2}$ das cultivares “BRS 195” e "BRS 225”, respectivamente. Para fins de avaliação, foram consideradas 8 linhas centrais da parcela, resultando em $6,8 \mathrm{~m}^{2}$ de área útil. Para o cálculo da adubação de base, foram observados os resultados da análise do solo descritos acima, sendo aplicados $254 \mathrm{~kg} \mathrm{ha}^{-1}$ de adubo da fórmula 08-30-20 + $0,3 \%$ de boro na linha de semeadura. Usou-se ainda 40 $\mathrm{kg} \mathrm{ha}^{-1}$ de nitrogênio em cobertura para a cultivar "BRS 225 ” e $80 \mathrm{~kg} \mathrm{ha}^{-1}$ para a cultivar "BRS 195", aplicados manualmente a lanço no início do perfilhamento (estádio 2 da escala Feeks-Large).

O delineamento experimental foi de blocos ao acaso, constituído de 4 tratamentos fitossanitários: fungicida (epoxiconazole 80g.i.a. ha ${ }^{-1}+$ pyraclostrobin 30gia ha ${ }^{-1}$ ), em duas aplicações nos estádios 8 e 10.5 da escala Feeks-Large; os elicitores goma xantana $(0,5 \mathrm{~g}$ $\left.\mathrm{L}^{-1}\right)$ e alicina $\left(0,87 \mathrm{mg} \mathrm{L}^{-1}\right)$, ambos em três aplicações nos estádios 6, 8 e 10.5 da escala Feeks-Large; e a testemunha (sem controle); cada qual com quatro repetições. Foram utilizadas as cultivares de cevada cervejeira "BRS 195” e "BRS 225”, sendo a primeira de ciclo aproximadamente 15 dias mais longo. Os elicitores e o fungicida foram aplicados com pulverizador costal equipado com ar comprimido, utilizando-se bico XR 110.02 com vazão de 200 litros ha-1.

Um total de cinco plantas por tratamento fitossanitário de cada repetição foi coletado em cinco épocas (09/08/04, 24/08/04, 06/09/04, 21/09/04 e 05/10/ 
04), correspondendo a 42 dias, 57 dias, 70 dias, 85 dias e 99 dias após a emergência, respectivamente. As folhas verdes tiveram sua área determinada utilizando-se o aparelho Win Rhizo (LA 1600, Régent Instruments Inc). Após a medição da área foliar, o material vegetal (folhas e colmos) foi pesado e levado à estufa a $65^{\circ} \mathrm{C}$, onde foi mantido por 72 horas para determinação da massa seca.

A análise de crescimento das cultivares foi realizada com o auxílio do Programa Computacional de linguagem basic AnaCres (PORTES \& CASTRO, 1991). Os índices estimados foram taxa de crescimento da cultura (TCC), taxa de crescimento relativo (TCR), taxa assimilatória líquida ou aparente (TAL), razão de área foliar (RAF) e área foliar específica (AFE). Para obtenção das curvas de regressão, foi utilizada a opção de MS quadrática x IAF quadrática com ajuste mínimo de $97,6 \%$.

A análise da variância e o teste de Tukey para comparação das médias de matéria seca e de área foliar foram realizados usando o programa estatístico Sanest (ZONTA \& MACHADO, 1999), analisando as duas cultivares separadamente, em esquema fatorial, sendo o fator "a” os quatro tratamentos fitossanitários e o fator "b” as cinco datas de avaliação, em nível de $5 \%$ de probabilidade de erro.

\section{RESULTADOS E DISCUSSÃO}

A diferença no ciclo das cultivares explica seu comportamento distinto em algumas das variáveis avaliadas no experimento. Na primeira avaliação, as duas cultivares encontravam-se praticamente na mesma fase de desenvolvimento (estádio 2 da escala FeeksLarge). No entanto, na última avaliação, a cultivar "BRS
225” encontrava-se no estádio de enchimento de grãos (10.5.4 da escala Feeks-Large), enquanto a "BRS 195" encontrava-se em espigamento pleno (10.5 da escala Feeks-Large).

O acúmulo de matéria seca nas duas cultivares foi semelhante, com um aumento linear e mais pronunciado nas três últimas coletas, que corresponderam aos estádios 8, 10.1 e 10.5 da escala Feeks-Large para a cultivar "BRS 195” e 10.1, 10.5 e 10.5.4 da escala Feeks-Large para a cultivar "BRS 225” (Tabela 1). Não foram constatadas diferenças significativas entre os tratamentos estudados, demonstrando que a aplicação de elicitores e fungicidas não altera o acúmulo de matéria seca total.

Apesar das diferenças em relação ao ciclo, ambas as cultivares atingiram médias de área foliar máxima aos 70 dias após a emergência, porém a área fotossinteticamente ativa superior foi obtida na cultivar “BRS 225”, cujo ciclo é menor (Tabela 2). Após esta fase, houve uma diminuição devido ao estádio de desenvolvimento, já que, a partir do emborrachamento, as folhas mais velhas estavam em processo de senescência. O resultado obtido nos diferentes tratamentos está de acordo com o observado por EPIPHANIO \& FORMAGGIO (1991) na cultura do trigo. A cultivar "BRS 195” mostrou um decréscimo mais lento, por apresentar um ciclo vegetativo mais longo quando comparado ao da “BRS 225”, que já se encontrava no estádio de enchimento de grãos na última coleta.

A TCR diminuiu da primeira para a última avaliação devido ao acúmulo contínuo de matéria seca no decorrer do período e pela diminuição da capacidade relativa da planta em produzir material novo. Apesar da diferença de ciclo das cultivares, observou-se que,

Tabela 1 - Médias de matéria seca total (gramas planta ${ }^{-1}$ ) das cultivares de cevada “BRS 195” e “BRS 225” após aplicação de elicitores e fungicidas.

\begin{tabular}{|c|c|c|c|c|c|}
\hline \multirow{2}{*}{ Tratamento } & \multicolumn{5}{|c|}{ Dias após a emergência } \\
\hline & 42 & 57 & 70 & 85 & 99 \\
\hline BRS 195 Testemunha & $0,43 \mathrm{~ns}^{*}$ & $1,07 \mathrm{~ns}$ & $2,05 \mathrm{~ns}$ & $5,50 \mathrm{~ns}$ & $6,48 \mathrm{~ns}$ \\
\hline BRS 195 Alicina & 0,40 & 0,94 & 2,23 & 5,57 & 7,51 \\
\hline BRS 195 Goma & 0,46 & 0,82 & 2,37 & 5,64 & 7,46 \\
\hline BRS 195 Fungicida & 0,42 & 1,01 & 2,24 & 6,06 & 7,30 \\
\hline BRS 195 Média & 0,43 & 0,96 & 2,22 & 5,69 & 7,19 \\
\hline BRS 225 Testemunha & $0,49 \mathrm{~ns}$ & $1,19 \mathrm{~ns}$ & 3,43 ns & $6,75 \mathrm{~ns}$ & $9,67 \mathrm{~ns}$ \\
\hline BRS 225 Alicina & 0,46 & 1,39 & 3,48 & 6,74 & 9,26 \\
\hline BRS 225 Goma & 0,48 & 1,25 & 3,41 & 6,48 & 8,94 \\
\hline BRS 225 Fungicida & 0,50 & 1,38 & 3,17 & 7,23 & 9,14 \\
\hline BRS 225 Média & 0,48 & 1,30 & 3,37 & 6,80 & 9,25 \\
\hline CV (\%) & 12,8 & & & & \\
\hline
\end{tabular}

* Comparação das médias na coluna pelo teste de Tukey em nível de 5\% de probabilidade de erro. 
Tabela 2 - Médias de área foliar ( $\mathrm{cm}^{2}$ planta $^{-1}$ ) das cultivares de cevada “BRS 195” e “BRS 225” após aplicação de elicitores e fungicidas.

\begin{tabular}{llllll}
\hline \multirow{2}{*}{ Tratamento } & \multicolumn{5}{c}{ Dias após a emergência } \\
\cline { 2 - 5 } & \multicolumn{1}{c}{42} & 57 & 70 & \multicolumn{1}{c}{85} & 99 \\
\hline BRS 195 Testemunha & $50,85 \mathrm{~ns} *$ & $120,64 \mathrm{~ns}$ & $245,17 \mathrm{~ns}$ & $262,30 \mathrm{~ns}$ & $181,14 \mathrm{~ns}$ \\
BRS 195 Alicina & 48,65 & 123,77 & 242,99 & 253,71 & 176,97 \\
BRS 195 Goma & 55,80 & 101,39 & 263,87 & 263,62 & 182,52 \\
BRS 195 Fungicida & 53,66 & 112,08 & 255,68 & 258,04 & 190,94 \\
BRS 195 Média & 52,24 & 114,47 & 251,93 & 259,42 & 182,89 \\
BRS 225 Testemunha & $67,31 \mathrm{~ns}$ & $155,41 \mathrm{~ns}$ & $307,47 \mathrm{~ns}$ & $247,83 \mathrm{~ns}$ & $215,35 \mathrm{~ns}$ \\
BRS 225 Alicina & 62,99 & 169,35 & 311,64 & 243,67 & 188,17 \\
BRS 225 Goma & 65,99 & 151,48 & 333,86 & 252,47 & 198,57 \\
BRS 225 Fungicida & 67,94 & 166,06 & 280,57 & 257,92 & 193,20 \\
BRS 225 Média & 66,06 & 160,58 & 308,39 & 250,47 & 198,82 \\
CV (\%) & 10,1 & & & & \\
\hline
\end{tabular}

* Comparação das médias na coluna pelo teste de Tukey em nível de 5\% de probabilidade de erro.

após 57 dias da emergência, os valores de TCR foram muito próximos em ambos os materiais genéticos e nos diferentes tratamentos (Figuras 1 e 2).

As curvas da TAL apresentaram valores mais elevados na primeira avaliação devido à menor área foliar existente e à elevada capacidade fotossintética dessas folhas (Figuras 3 e 4). Posteriormente houve uma diminuição acentuada, voltando a aumentar a eficiência fotossintética a partir de 57 dias após a emergência. Este acréscimo deve-se principalmente à melhoria da eficiência na atividade fotossintética devida ao início do processo de senescência das folhas mais velhas, resultando com isso num aumento considerável na TAL. Esta maior eficiência das folhas remanescentes (folha bandeira, folha bandeira -1 e folha bandeira -2) foi observada por FLOSS \& ALVES (1995), avaliando a contribuição relativa das folhas no rendimento e na qualidade de grãos de aveia. Ambas as cultivares apresentaram valores de TAL próximos, indicando que a menor duração do ciclo da cultivar “BRS 225” é compensada por um maior investimento em arquitetura foliar, pois

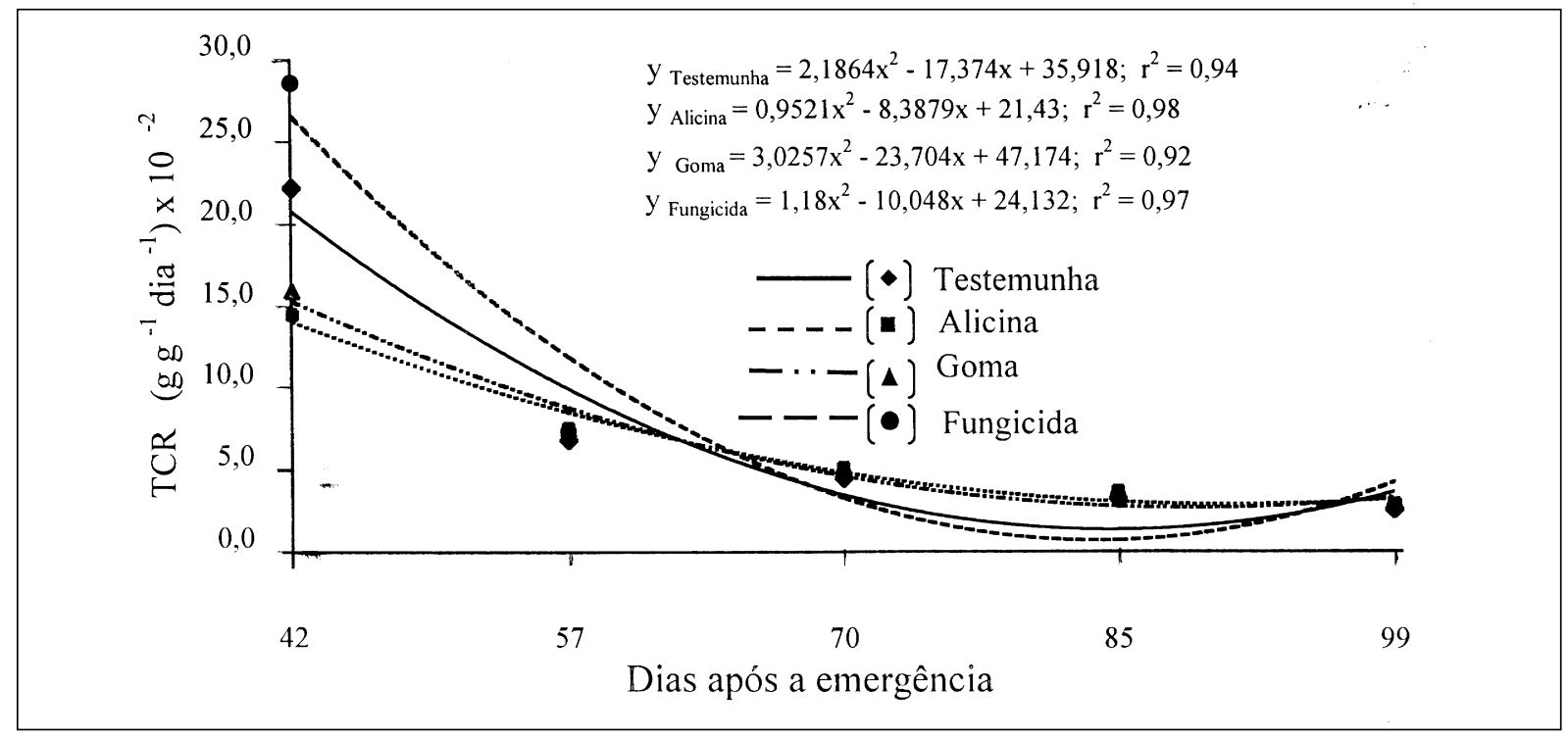

Figura 1 - Taxa de crescimento relativo da cultivar de cevada "BRS 195” após aplicação de elicitores e controle químico.

Ciência Rural, v.36, n.4, jul-ago, 2006. 


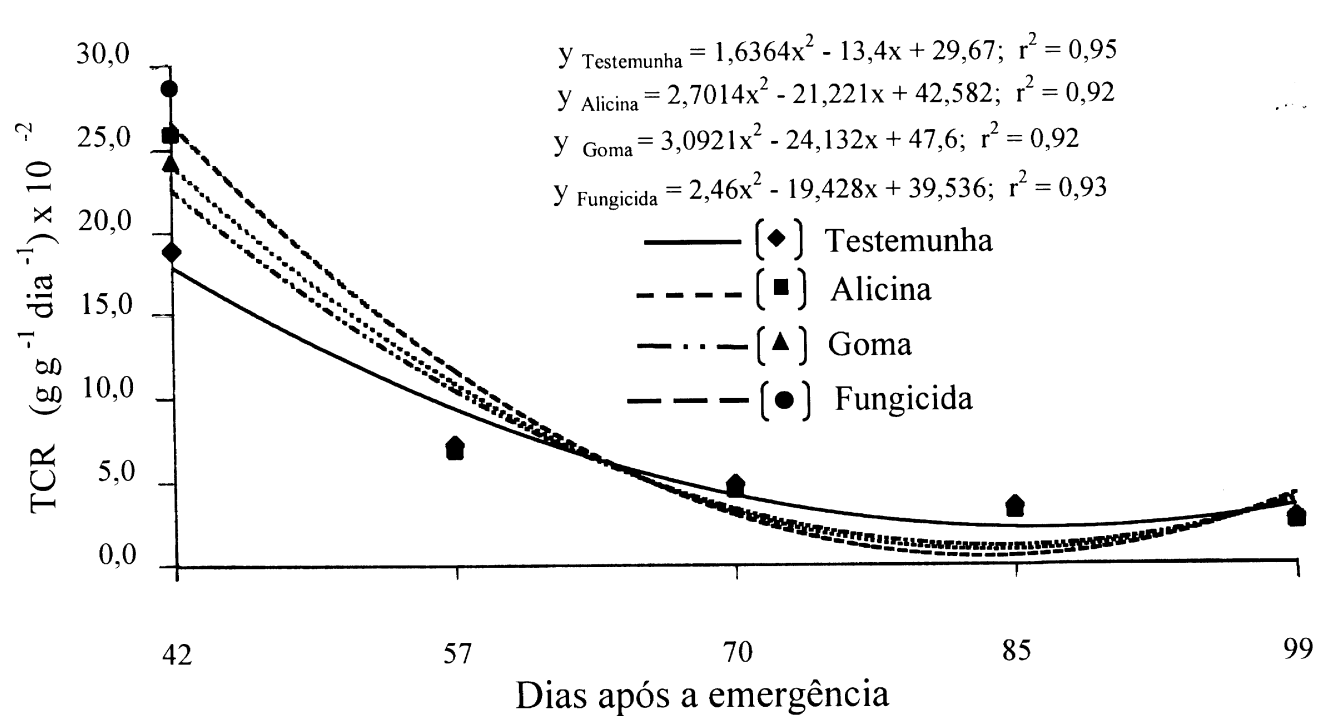

Figura 2 - Taxa de crescimento relativo da cultivar de cevada “BRS 225” após aplicação de elicitores e controle químico.

houve semelhança na eficiência de assimilação líquida de carbono por unidade de área. O comportamento semelhante dos tratamentos estudados indica não haver efeitos seus sobre o balanço líquido da fotossíntese.

Até o momento, nenhum estudo semelhante, avaliando criteriosamente o desenvolvimento de variedades de cevada cultivadas no Brasil após a aplicação de elicitores, foi desenvolvido e, caso seja comprovada, em condições de campo, a eficiência observada em casa de vegetação, estes poderão servir como alternativas ao controle com fungicidas.

\section{CONCLUSÕES}

O desenvolvimento das cultivares de cevada “BRS 195” e “BRS 225” não é afetado pela aplicação

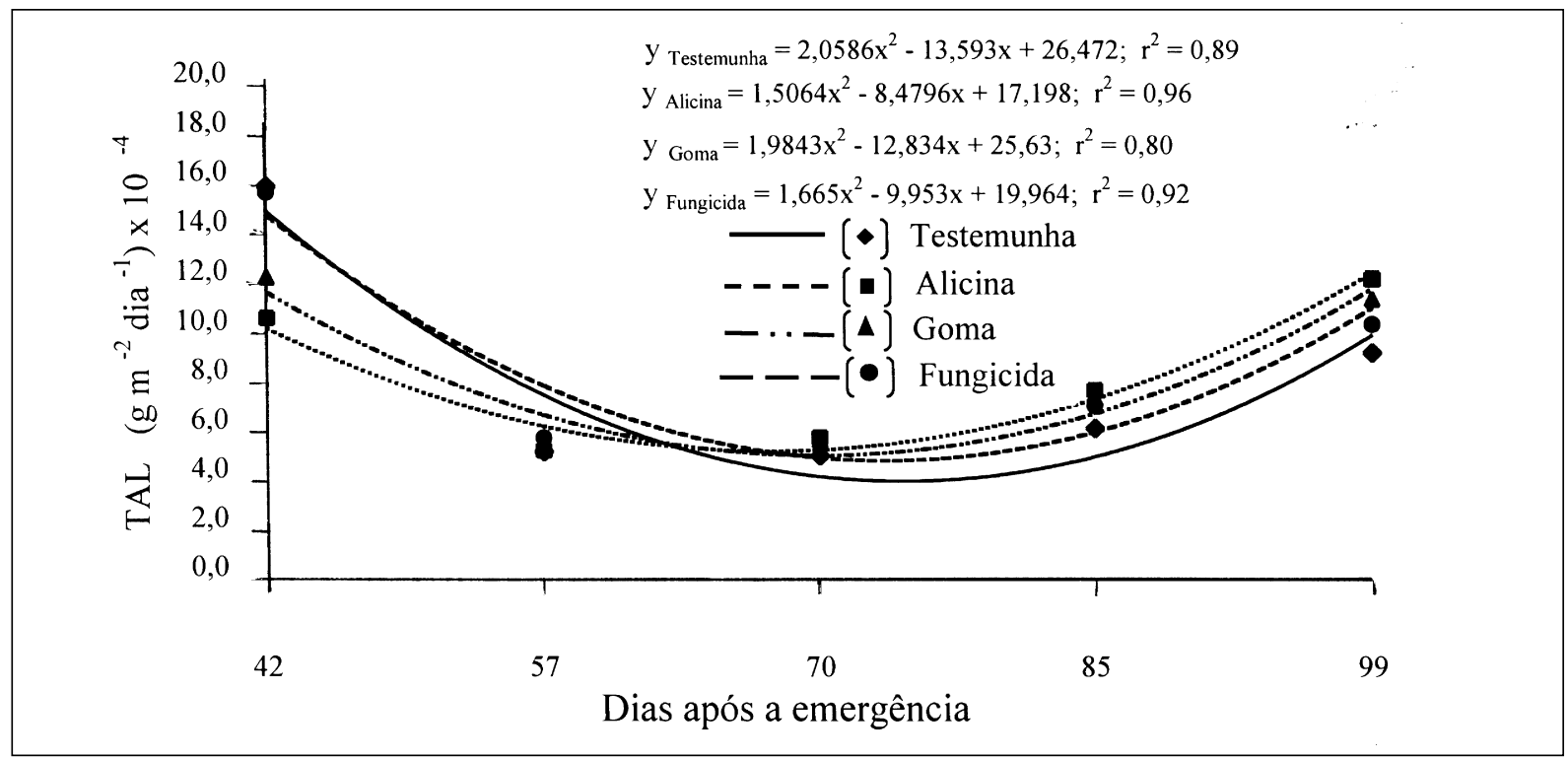

Figura 3 - Taxa assimilatória líquida da cultivar de cevada "BRS 195” após aplicação de elicitores e controle químico.

Ciência Rural, v.36, n.4, jul-ago, 2006. 


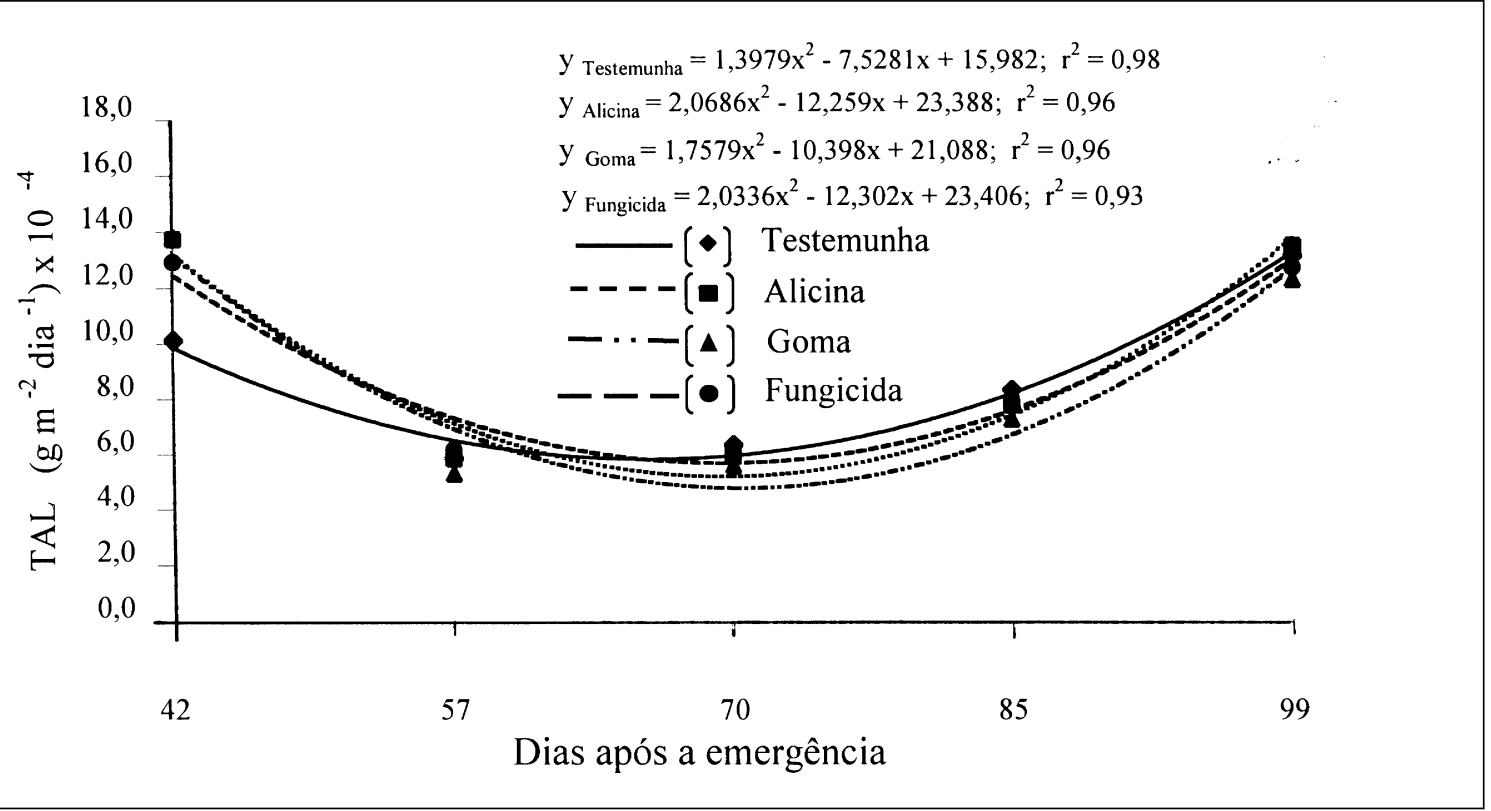

Figura 4 - Taxa assimilatória líquida da cultivar de cevada "BRS 225” após aplicação de elicitores e controle químico.

dos elicitores alicina e goma xantana nem pelo tratamento com o fungicida epoxiconazole + pyraclostrobin, quando comparadas com plantas não tratadas. Embora os elicitores induzam alterações no metabolismo vegetal, as quais são responsáveis pela proteção da planta ao ataque do fungo Bipolaris sorokiniana, essas alterações não resultam em diferenças significativas do desenvolvimento vegetal.

\section{REFERÊNCIAS}

ARIAS, G. Mejoramiento genético y producción de cebada cervecera en América del Sur. Santiago, Chile: Dirección de producción y protección vegetal (FAO), Oficina Regional de la FAO para América Latina y el Caribe, 1995. 162p.

BACH, E.E. Distinção morfológica e isoenzimática de Bipolaris spp. e Drechslera tritici-repentis do trigo: aspectos bioquímicos nas interações e indução de resistência. 1997. 132f. Tese (Doutorado em Fitopatologia) - Escola Superior de Agricultura Luiz de Queiróz, Universidade de São Paulo.

BACH, E. et al. Induced resistance against Bipolaris bicolor, Bipolaris sorokiniana and Drechslera tritici-repentis in wheat leaves by xantham gum and heat-inactivate conidia suspension. Journal of Phytopathology, v.151, p.411-418, 2003.

BENHAMOU, N. Elicitor-induced plant defence pathways. Trends Plant Sci, v.1, p.233-240, 1996.

BENINCASA, M.P.M. Análise de crescimento de plantas: noções básicas. Jaboticabal: FCAV-UNESI, 1988. 42p.

CASTRO, O. L. et al. Uso da goma xantana como indutor de resistência em plantas de cevada (cultivares AF 94135 e
EMBRAPA 128) contra Bipolaris sorokiniana. In: REUNIÃO ANUAL DE PESQUISA DE CEVADA, 21., 2001, Guarapuava. Anais e ata... Guarapuava: EMBRAPA, 2001. p.559-567.

CASTRO, O.L. et al. Efeito da goma xantana em planta de cevada (variedade EMBRAPA 129) no controle de Bipolaris sorokiniana. In: REUNIÃO ANUAL DE PESQUISA DE CEVADA, 22., 2002, Passo Fundo. Anais e ata... Passo Fundo: EMBRAPA, 2002. p.531-540.

EMBRAPA - CENTRO NACIONAL DE PESQUISA DE SOLOS. Sistema brasileiro de classificação de solos. Brasília: Embrapa, Rio de Janeiro, 1999. 412p.

EMPRESA BRASILEIRA DE PESQUISA AGROPECUÁRIA. Indicações técnicas para produção de cevada cervejeira: safras 2003 e 2004. Comissão de Pesquisa de Cevada. Passo Fundo: Embrapa Trigo, 2003. 78p.

EPIPFANIO, J.C.N.; FORMAGGIO, A.R. Sensoriamento remoto de três parâmetros de trigo e de feijão. Pesquisa agropecuária brasileira, Brasília, v.26 n.10, p.1615-1624, 1991.

FLOSS, E.; ALVES, L.M.M. Contribuição relativa da fotossíntese das folhas no crescimento e qualidade de grãos de aveia, safra 1993. In: REUNIÃO DA COMISSÃO SULBRASILEIRA DE PESQUISA DE AVEIA, 18., 1995, Guarapuava. Resultados experimentais... Guarapuava: FAPA, 1995. p.261-263.

GATZ, C. Chemical control of gene expression. Annual Review of Plant Molecular Biology, v.48, p.89-108, 1997.

GUZZO, S.D. et al. Crude exopolysaccharides (EPS) from Xanthomonas campestris $p v$. manihotis, $\mathrm{X}$. campestris $\mathrm{pv}$. campestris and commercial xanthan gum as inducers of protection in coffee plants against Hemileia vastatrix. Journal of Phytopathology, Berlin, v.139, p.119-128, 1993.

Ciência Rural, v.36, n.4, jul-ago, 2006. 
HERMANN, K.M.; WEAVER, L. M. The shikimate pathway. Annual Review of Plant Physiology and Plant Molecular Biology, v.50, p.473-503, 1999.

PORTES, T.A.; CASTRO, L.G. Análise de crescimento de plantas: Um programa computacional auxiliar. Revista Brasileira de Fisiologia Vegetal, São Paulo, v.3 n.1, p.5356, 1991

RODRIGUES, E.L. et al. Utilização da alicina como indutor de resistência em plantas de cevada (variedade EMBRAPA 128) contra Bipolaris sorokiniana. In: REUNIÃO ANUAL DE PESQUISA DE CEVADA, 22., 2002, Passo Fundo. Anais e ata... Passo Fundo: EMBRAPA, 2002. p.519530 .

RODRIGUES, E.L.; BACH, E.E. Alicina como indutor de resistência na cultivar de cevada AF 94135. In: REUNIÃO
ANUAL DA PESQUISA DE CEVADA, 23., 2003, Passo Fundo. Anais e ata... Passo Fundo: EMBRAPA, 2003. p.557-570.

TONON, J. Cevada: as principais doenças fúngicas. Correio Agrícola Bayer, v.2, p.12-15, 1992.

TURQUETTI, A.A. et al. Testes in vitro de antagonismo entre Trichoderma sp. e Bipolaris sorokiniana da cevada. In: REUNIÃO ANUAL DE PESQUISA DE CEVADA, 21., 2001. Guarapuava. Anais e ata... Passo Fundo: Embrapa Trigo, 2001. p.457-463

ZONTA, E.P.; MACHADO, A.A. SANEST - Sistema de análise estatística para microcomputadores. Registro na secretaria especial de informática n. 066060, Pelotas, 1999. 96p. (Documentos) 